\title{
A prospective evaluation of the influence of three bariatric procedures on insulin resistance improvement. Should the extent of undiluted bile transit be considered a key postoperative factor altering glucose metabolism?
}

\author{
Łukasz Kaska' ${ }^{1}$, Monika Proczko ${ }^{1}$, Piotr Wiśniewski ${ }^{1}$, Marta Stankiewicz $^{2}$, Derek Gill ${ }^{1}$, Zbigniew Śledziński $^{1}$ \\ ${ }^{1}$ Department of General, Endocrine and Transplant Surgery, Medical University of Gdansk, Gdansk, Poland \\ 2Department of Clinical Nutrition, Medical University of Gdansk, Gdansk, Poland
}

Videosurgery Miniinv 2015; 10 (2): 213-228

DOI: $10.5114 /$ wiitm.2015.52062

\begin{abstract}
Introduction: Insulin resistance (IR), the essential step in development of type 2 diabetes mellitus (T2DM), resolves quickly after bariatric surgery, but the effectiveness depends on the type of the procedure. Although the long-term influence on IR improvement is well documented, the mechanisms of the ultra-fast response after restrictive and bypass procedures require explanation.

Aim: To determine IR evolution from the initial preparative period to 6 months after the operation, exposing the rapid postoperative response while comparing the 3 bariatric methods, with the belief that the metabolic effect may be correlated with anatomical combinations.

Material and methods: From January to December, 2013, a cohort of severely obese, insulin resistant individuals recruited to the prospective study underwent laparoscopic sleeve gastrectomy (SG-30), Roux-en-Y gastric bypass (RYGB-30) and one-anastomosis gastric bypass (OAGB-30). Main laboratory parameters of glucose metabolism were evaluated in fasting patients preoperatively, 4 days and 1, 3 and 6 months after surgery.

Results: Within the whole observation period the most significant improvement in homeostasis model assessment for IR (HOMA-IR) was observed in the first 4 days after each operation. The decrease of HOMA-IR was higher $(p<0.0001)$ in gastric bypass groups than in patients after SG $(-41 \%)$. The difference between bypass groups favors OAGB over RYGB (63 vs. $-56 \%, p=0.0489)$.

Conclusions: Among all bariatric management factors, operation type is the most important in IR improvement. The significant difference in response after SG vs. RYGB and OAGB supports the concept of metabolic competence of duodeno-jejunal exclusion. Altered bile flow after duodeno-jejunal exclusion may be responsible for enhanced glucose metabolism improvement.
\end{abstract}

Key words: insulin resistance, type 2 diabetes mellitus, sleeve gastrectomy, Roux-en-Y gastric bypass, one-anastomosis gastric bypass, homeostasis model assessment for insulin resistance, role of bile.

\section{Introduction}

The increased risk of premature death in morbidly obese individuals is strongly associated with type 2 diabetes mellitus (T2DM) and its complications. Insulin resistance (IR) has been recognized as the essential step in development of T2DM [1-4]. The accelerated insulin production and secretion required

\section{Address for correspondence}

Łukasz Kaska MD, PhD, Department of General, Endocrine and Transplant Surgery, Medical University of Gdansk, 17 a Smoluchowskiego St, 80-952 Gdansk, Poland, phone: +48 501677 644, e-mail: lukasz.kaska@wp.pl 
to balance the plasma glucose level lead progressively to $\beta$-cell dysfunction and further development of the disease. Decreased calorie consumption, increased caloric metabolism and the resulting weight loss can theoretically invert this unfavorable trend and improve the course of T2DM [5-8]. This recommended first line treatment, however, seems to be insufficient on its own in long-term observations and leads to additional bariatric procedures to help prevent the global and individual hazards of diabetes progression [9-11]. The emerging data underline that bariatric surgery may provide a more sustained and effective treatment for obesity and its related diseases including T2DM [12-15].

The surgical methods currently accepted in the bariatric world - sleeve gastrectomy (SG), gastric bypass (GB) with its variations, and biliopancreatic diversion/duodenal switch (BPD/DS) - present different modifications of metabolic mechanisms, but all reduce calorie intake as their primary function, leading to body fat reduction [16-20].

The previously mentioned fat deposits are the critical factor in impaired insulin function; thus weight reduction must result in improved glucose metabolism [21, 22].

Many recent studies have shown that the modification of gastro-intestinal hormone activity following bariatric surgery, particularly related to the effects of incretin, may support or even initiate better metabolic management, especially following intestinal bypassing procedures [23-26].

The observation of the change in the hormonal profile influencing IR a few days after GB procedures showed that the key mechanism in improving IR was addressed [26]. This vital shift was evidenced by not only the lack of significant body mass reduction, but also the lack of initiation of incretin-related mechanisms dependent on oral food intake [26].

A number of meta-analyses have reported that glucose metabolism was significantly corrected at 2 weeks following GB and BPD/DS procedures. Faria et al. based on HOMA-IR assessment observed more rapid improvement of IR as early as 3 days following Roux-en-Y gastric bypass (RYGB) [27].

This phenomenon corresponds with clinical reports of some diabetic patients being discharged without anti-diabetic medications just a few days after their GB surgery [28-31].

Despite many reports dedicated to this issue, there is still no comprehensive hypothesis explaining the rapid response following GB procedures.
One theory, proposed by Pournanras et al. [32], concerns the signaling role of bile and its components, represented by bile acids (BA) reabsorbed by the portal circulation, in rapid glucose control. Elevated concentrations of $\mathrm{BA}$ in the blood are believed to be strongly linked to the improvement of glycemic metabolism, therefore suggesting that surgical procedures in which undiluted bile is transported via a long section of the small intestine excluded from food passage may be a significant factor.

The supreme effectiveness in T2DM resolution after BPD/DS [16], in which the biliary limb (BL) is designed to be much longer than the alimentary limb (AL), in contrast to that in RYGB, may be partially explained by the above-mentioned mechanism [33-35]. Moreover, one-anastomosis gastric bypass (OAGB), the bariatric procedure designed to be a more feasible modification of the gastric bypass, demonstrates greater similarity to BPD/DS than to RYGB in long-term assessment [36]. The significantly longer undiluted bile transit in the bypassed portion of the gastrointestinal (GI) tract in OAGB and BPD/ DS as opposed to RYGB may be considered as the deciding factor in the endocrine anti-diabetic mechanism. What should be emphasized here is that the length of the small intestine distally to the site of initial mixing of food with biliopancreatic juice is almost equal in both forms of the GB. Therefore the intestinal capacity responsible for the calorie intake remains comparable.

Despite many controversies concerning the longterm functional results of OAGB, its metabolic profile has been widely accepted, and this GB modification is currently regarded by many as a distinct procedure [36-39].

The primary objective of this prospective randomized study was to assess the changes in the main laboratory parameters of glucose metabolism and determine the IR evolution from the time of the initial preoperative visit until the 6-month follow-up consultation, exposing the significance of the ultra-fast postoperative response while comparing the 3 bariatric methods, with the belief that the degree of metabolic effect may be correlated with different anatomical combinations.

The authors attempted to investigate whether the extreme calorie restriction in the first 4 postoperative days may be considered as the sole key factor of IR improvement or if the hormonal advantages resulting from duodeno-intestinal exclusion should 
be recognized as the most significant mechanism in glycemic control. Sleeve gastrectomy as a pure restrictive procedure and two types of gastric bypass were selected for the comparison to try to resolve this question. The results after RYGB vs. OAGB, where the main difference was the length of the $B L$, verify the theory of the role of the bile components in the hormonal mechanism of glucose metabolism control.

\section{Material and methods}

From January to December 2013, a cohort of 90 severely obese individuals with a body mass index $(\mathrm{BMI})$ in the range 35-55 were recruited to the prospective study. The main inclusion criterion, apart from morbid obesity, was the impairment of glucose tolerance, defined as a homeostatic model assessment-insulin resistance (HOMA-IR) formula value > 2.5 [40]. Patients receiving anti-diabetic or other hormonal medications were not included in the investigation. Patients suffering from diseases seriously affecting glucose homeostasis were also initially excluded.

Morbid obesity was the basic indication for the operation. All of the patients met the IFSO criteria [41].

The patients enrolled in the study were consecutively divided into 3 equal groups of 30: sleeve gastrectomy (SG), Roux-en-Y gastric bypass (RYGB), and one-anastomosis gastric bypass (OAGB).

Regardless of the procedure allocation, all of the patients completed the preoperative 3-month preparation period, which consisted of a low-calorie diet (1000-1200 kcal/day) and psychological management. In order to reduce the risk of perioperative complications and adverse events, patients were trained on how to reduce food intake and how to control their eating drive and to adapt to the postoperative change of the GI tract anatomy.

The operations were performed laparoscopically following the techniques described in published materials [42, 43].

A 36 Fr calibration tube was used to confirm volume restriction of the gastric sleeve or pouch (volume ca $40 \mathrm{ml}$ ). Because a long and narrow gastric pouch was constructed in OAGB to reduce the risk of bile reflux, the same type of gastric tube was used in RYGB procedures to create similar restriction conditions for the comparison.

The continuity of the digestive tract in SG was preserved, and no exclusion of the intestine was performed. The length of the intestinal loops excluded from mixed food and biliopancreatic content in GB operations was equal and measured intraoperatively $250 \mathrm{~cm}$ but in different combinations according to the type of the procedure. The extent of the common limb was therefore left equal. The scheme of the procedures is shown in Figure 1.

All but 3 complicated patients were discharged home on the $4^{\text {th }}$ postoperative day after laboratory tests. They were provided with a detailed dietary plan to prevent alimentary deficiencies.

The total observation period consisted of 5 phases starting with the initial visit then progressing in the perioperative period lasting 9 months, and was scheduled as shown in Table I.

Blood samples were collected after an overnight fast during the initial visit (ini) and during the following checkpoints: day 0 (OD), day 4 (4D), and 1,3 and 6 months $(1 M, 3 M, 6 M)$ after the surgery. According to the protocol, such parameters as glucose and insulin levels were measured (INI, OD, 4D, 1M, 3M, 6M), whereas IR was calculated using the HOMA-IR formula (glucose $x$ insulin /405) [44]. Glycosylated hemoglobin $\left(\mathrm{HbA}_{1 \mathrm{c}} \%\right)$ was determined at the time points ini, $3 \mathrm{M}$, and $6 \mathrm{M}$. Finally, BMI measurement was performed initially, after the preoperative 3-month preparation period, then 1 month, 3 months, and 6 months after the operation.

Although the blood tests included the blood lipid values, the authors decided not to attach results in the description to avoid blurring the main concept of the study.

All analyses were performed in the Central Hospital Laboratory using the Abbot Architect Cl8200 automated clinical chemistry analyzer. $\mathrm{HbA}_{1 \mathrm{c}}$ levels were determined by ion-exchange high-performance liquid chromatography (HPLC).

The scope, methodology and assumptions of the study were accepted by the local bioethical committee of the Medical University of Gdansk, Poland.

\section{Statistical analysis}

Statistical calculation was performed with the SPSS package, using one-way ANOVA with post-hoc Bonferroni.

Longitudinal analysis was calculated comparing the present results to previous and basic checkpoints. Statistical significance was set at $p<0.05$. 


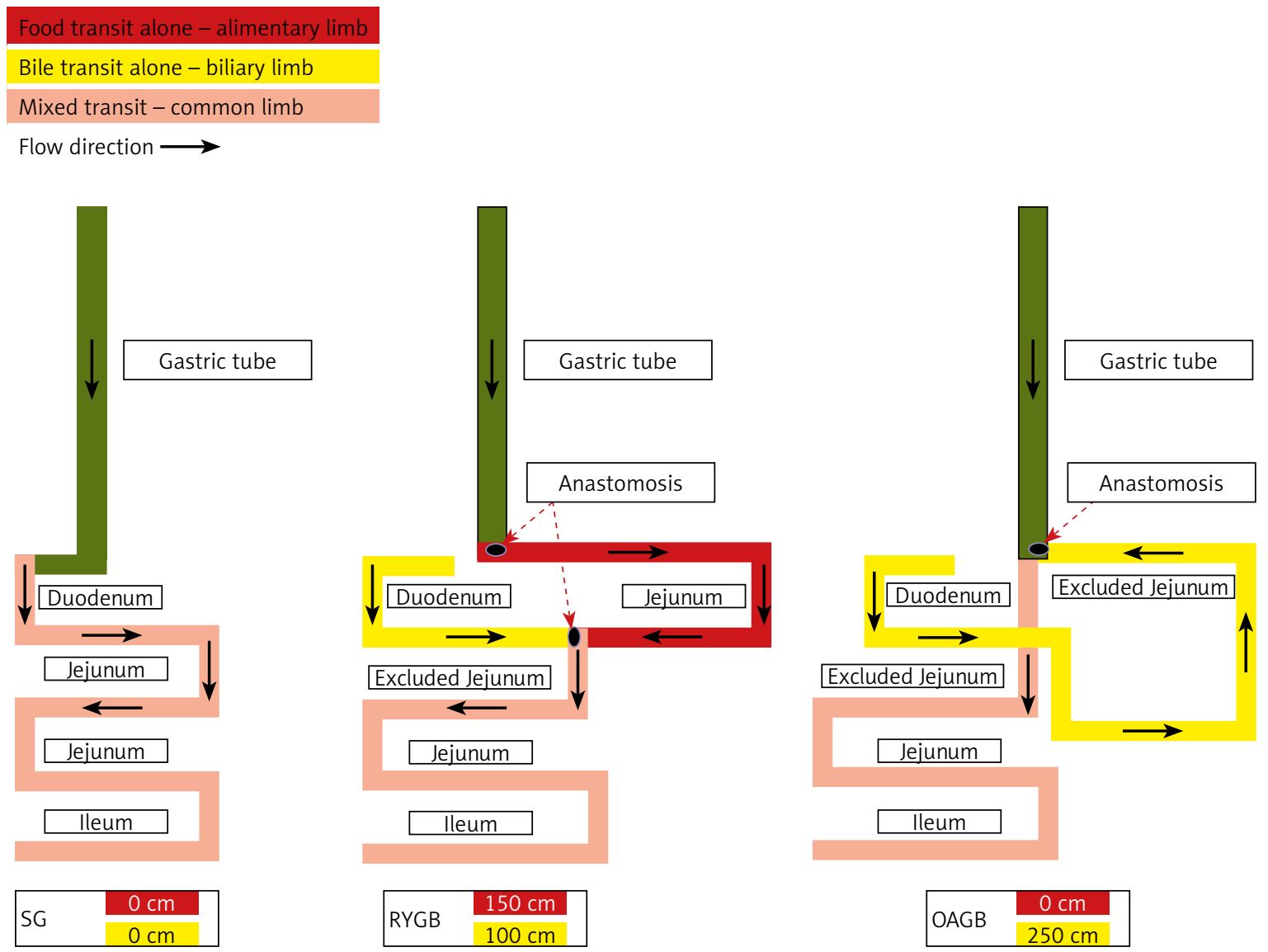

Figure 1. Scheme of the procedures

Table I. Observation periods and time points

\begin{tabular}{|c|c|c|c|}
\hline Phase & $\begin{array}{l}\text { Period/time } \\
\text { points }\end{array}$ & Duration & Specification \\
\hline 1 & ini-OD & 3 months & $\begin{array}{l}\text { From initial preoperative visit until the day of admission to the hospital. The phase } \\
\text { when the influence of the preparative low calorie diet (ca 1000-1200 kcal/ day) } \\
\text { may be observed }\end{array}$ \\
\hline 2 & $0 D-4 D$ & 5 days & $\begin{array}{c}\text { From the day of admission until the day of discharge from the hospital. The phase } \\
\text { when patients did not initiate eating (only clear fluids orally), therefore the effect } \\
\text { of the operation and extreme calorie restriction can be observed }\end{array}$ \\
\hline 3 & $4 \mathrm{D}-1 \mathrm{M}$ & 1 month & $\begin{array}{l}\text { From the day of discharge until the end of } 1^{\text {st }} \text { postoperative month. The phase } \\
\text { when only the low calorie/low volume diet may have influence on the IR result }\end{array}$ \\
\hline 4 & $1 M-3 M$ & 2 months & $\begin{array}{l}\text { From the of end of the } 1^{\text {st }} \text { postoperative month until the end of } 3^{\text {rd }} \text { postoperative } \\
\text { month. The phase when additional moderate weight/fat reduction may contribute } \\
\text { to IR improvement }\end{array}$ \\
\hline 5 & $3 M-6 M$ & 3 months & $\begin{array}{c}\text { From the end of } 3^{\text {rd }} \text { to } 6^{\text {th }} \text { postoperative month. The phase when remarkable } \\
\text { weight/fat reduction may additionally influence IR }\end{array}$ \\
\hline
\end{tabular}

\section{Results}

From the total group of 90 cases, 9 patients (6 from SG and 3 from RYGB) were excluded due to issues that could interfere with the results. The list of patients and the reason for exclusion are presented in Figure 2.

Power calculation was performed a priori. With a significance level of 0.05 , three groups, a power of at least $85 \%$ and expectation of a large effect 
$(f=0.40)$, the total required sample size was calculated for a minimum of 72 objects. Leven's test revealed homogeneity within the groups $(p>0.05)$.

The initial mean parameters of glucose metabolism as well as the main demographic variables were comparable in the 3 groups and are detailed in Table II.

There were no postoperative deaths in the investigated groups. Apart from 2 excluded patients from the RYGB and SG groups who experienced a pulmonary embolism and 1 RYGB patient who experienced postoperative bleeding requiring reoperation $12 \mathrm{~h}$ after the surgery, no major complications were observed. Gastritis was diagnosed in 2 patients after SG (8.3\%) and ulceration in the pouch-jejunum anastomosis was diagnosed in 3 patients after RYGB (11.1\%) 6 months after the procedures. Only 2 patients complained of persistent biliary reflux episodes up to 1 month after OAGB, but the symptoms passed without any treatment. Episodes of hypoglycemia (glucose $<70 \mathrm{mg} \%$ ) were experienced postopera-

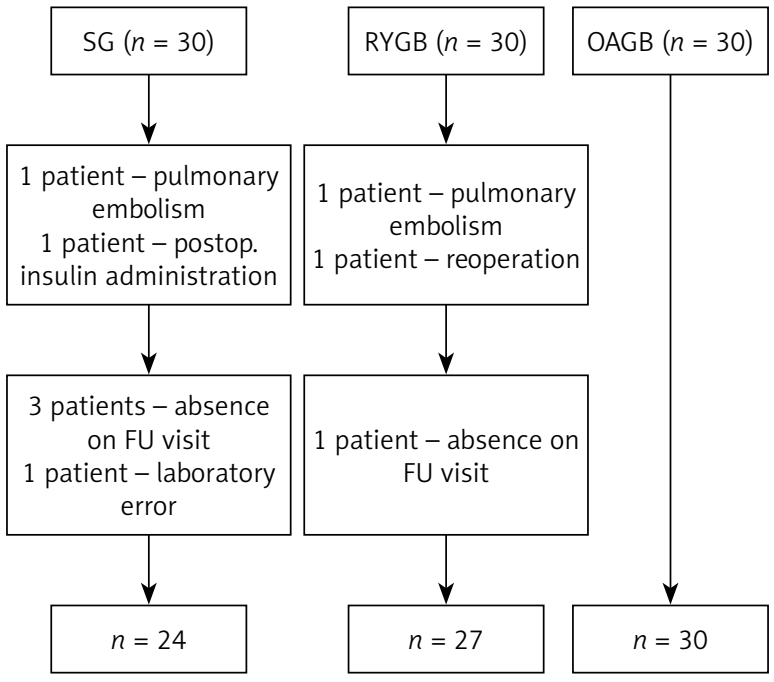

Figure 2. Patients excluded from the study tively by almost half of the patients (SG 50\%, RYGB $40.7 \%$, OAGB $53.3 \%$ ) but were treated by means of dietary correction. Only 10 patients reported hypo-

Table II. Characteristics of the included patients on the initial visit

\begin{tabular}{|c|c|c|c|c|c|c|}
\hline \multirow[t]{2}{*}{ Preoperative parameters (INI) } & \multicolumn{2}{|c|}{ SG $(n=24)$} & \multicolumn{2}{|c|}{$\operatorname{RYGB}(n=27)$} & \multicolumn{2}{|c|}{ OAGB $(n=30)$} \\
\hline & Mean & SD & Mean & SD & Mean & SD \\
\hline Age & 43.3 & 12.4 & 44.3 & 12.1 & 45 & 9.8 \\
\hline Male/female & $6 / 18$ & & $7 / 20$ & & $10 / 20$ & \\
\hline $\mathrm{BMI}\left[\mathrm{kg} / \mathrm{m}^{2}\right]$ & 45.90 & 6.52 & 43.99 & 5.89 & 45.92 & 4.82 \\
\hline Weight [kg] & 132.3 & 12.7 & 128.9 & 16.5 & 131.4 & 17.1 \\
\hline Obesity evolution [years] & 19.2 & 11.2 & 21.8 & 12.1 & 22.5 & 10.2 \\
\hline Glucose [mg/dl] & 108.54 & 14.60 & 106.22 & 14.97 & 110.27 & 12.6 \\
\hline Insulin $[\mu \mathrm{UI} / \mathrm{I}]$ & 17.17 & 4.31 & 17.83 & 5.66 & 17.79 & 4.52 \\
\hline HOMA-IR & 4.60 & 1.53 & 4.79 & 2.02 & 4.93 & 1.65 \\
\hline $\mathrm{HbA}_{1 \mathrm{c}}$ & 6.06 & 0.34 & 6.08 & 0.59 & 6.06 & 0.27 \\
\hline \multirow[t]{2}{*}{ Parameter } & \multicolumn{2}{|c|}{ SG $(n=24)$} & \multicolumn{2}{|c|}{ RYGB $(n=27)$} & \multicolumn{2}{|c|}{ OAGB $(n=30)$} \\
\hline & $n$ & $\%$ & $n$ & $\%$ & $n$ & $\%$ \\
\hline Dyslipidemia & 23 & 95.8 & 25 & 92.6 & 26 & 86.6 \\
\hline Hypertension & 21 & 87.5 & 24 & 88.9 & 25 & 83.3 \\
\hline Arthropathy & 8 & 33.3 & 8 & 29.6 & 11 & 36.6 \\
\hline GERD & 5 & 20.8 & 7 & 25.9 & 7 & 23.3 \\
\hline Sleep apnea & 3 & 12.5 & 4 & 14.8 & 4 & 13.3 \\
\hline Asthma & 2 & 8.3 & 3 & 11.1 & 3 & 10 \\
\hline Psoriasis & 1 & 4.2 & 2 & 7.4 & 1 & 3.3 \\
\hline
\end{tabular}


Table III. Postoperative adverse events

\begin{tabular}{|c|c|c|c|c|c|c|}
\hline & \multicolumn{2}{|c|}{ SG $(n=24)$} & \multicolumn{2}{|c|}{ RYGB $(n=27)$} & \multicolumn{2}{|c|}{ OAGB $(n=30)$} \\
\hline & $n$ & $\%$ & $n$ & $\%$ & $n$ & $\%$ \\
\hline \multicolumn{7}{|l|}{ Adverse events $<30$ days } \\
\hline Hypoglycemia episodes & 13 & 54.2 & 13 & 48.2 & 17 & 56.6 \\
\hline Constipation episodes & 9 & 37.5 & 10 & 37 & 5 & 16.7 \\
\hline Vomiting episodes & 6 & 25 & 7 & 25.9 & 7 & 23.3 \\
\hline Diarrhea & 1 & 4.2 & 6 & 22.2 & 9 & 30 \\
\hline Persistent biliary reflux & 0 & & 0 & & 2 & 6.7 \\
\hline \multicolumn{7}{|l|}{ Adverse events $>30$ days } \\
\hline GERD & 4 & 16.7 & 0 & & 0 & \\
\hline Hypoglycemia episodes & 5 & 20.8 & 4 & 14.8 & 5 & 16.7 \\
\hline Gastritis or pouchitis & 2 & 8.3 & 1 & 3.7 & 1 & 3.3 \\
\hline Hypoalbuminemia & 3 & 12.5 & 5 & 18.5 & 7 & 23.3 \\
\hline Anemia & 2 & 8.3 & 3 & 11.1 & 5 & 16.7 \\
\hline Iron deficiency & 2 & 8.3 & 3 & 11.1 & 5 & 16.7 \\
\hline Vit $\mathrm{B}_{12}$ deficiency & 0 & & 0 & & 1 & 3.3 \\
\hline Vit $\mathrm{D}_{3}$ deficiency & 6 & 24 & 6 & 22.2 & 9 & 30 \\
\hline Diarrhea & 0 & & 3 & 11.1 & 5 & 16.7 \\
\hline $\begin{array}{l}\text { Ulceration of the pouch-jeju- } \\
\text { nal anastomosis }\end{array}$ & - & & 3 & 11.1 & 0 & \\
\hline
\end{tabular}

glycemic episodes later than 30 days after the procedure. There was no need to control glucose levels with anti-diabetic medications up to the 6-month postoperative checkpoint in all but 1 patient, who had to be excluded due to single doses of insulin administration in the first 2 days after SG. The adverse postoperative events are listed in Table III.

In the total 9-month period of observation (including the 3-month preoperative preparation), relevant improvement of the main parameters of glucose metabolism was observed in all 3 groups.

Reduced calorie intake to $1000-1200 \mathrm{kcal}$ in the preoperative period in patients awaiting surgery (phase 1), which led to weight reduction (3.3-4.5 BMI points), resulted in approximately a $20 \% \mathrm{im}$ provement (SG 16.73\%, RYGB 20.46\%, OAGB 21.3\%) of the HOMA-IR index.

However, the most spectacular insulin sensitivity change was observed in the first 4 days after surgery (Phase 2). The decrease of HOMA-IR at 4 days after surgery compared to the preoperative value (DO) was significantly higher in gastric bypass groups than in patients after pure restrictive surgery: OAGB
$-2.44(-63 \%)$, RYGB $-2.14(-56 \%)$, vS. SG -1.57 $(-41 \%)$. The difference between the BP groups was noticeable, favoring OAGB over RYGB. The change of HOMA-IR postoperatively is shown in Figure 3.

Though the trend of insulin resistance improvement was observed in all phases, the HOMA-IR levels on the $4^{\text {th }}$ postoperative day were not significantly different from values at 1, 3, and 6 months in all groups. They are detailed in Table IV and Figures 4, 5 .

While the drop of insulin level was the key variable influencing the postoperative ultra-fast HOMA-IR decrease, the low plasma glucose was the deciding factor in the longer term of the postoperative period in phases $3-5$, especially in OAGB patients (Figures 6-8).

In the total 9-month period of observation, differences in $\mathrm{BMI}$ values $(\triangle \mathrm{BMI}, \% \Delta \mathrm{BMI})$ of -10.2 $(-22.2 \%)$ after SG, -14.1 (-32.1\%) after RYGB, and $-16.5(-36.4 \%)$ after OAGB were observed. The evolution of BMI is shown in Figure 9.

The HOMA-IR improvement accompanied the weight and body fat reduction in the 3-month prepa- 


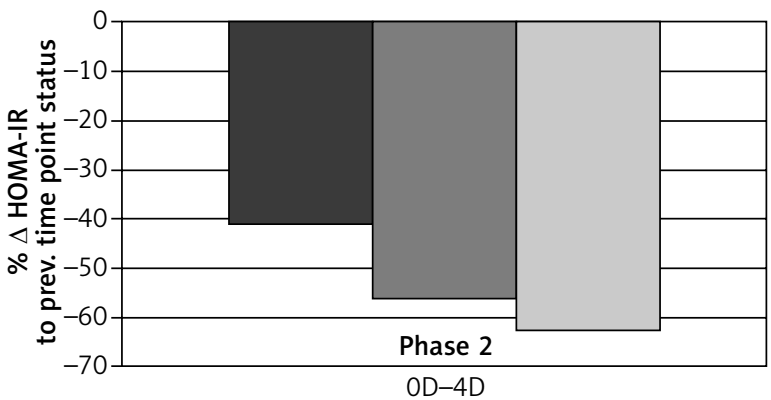

\begin{tabular}{|l|c|}
\hline$\square$ SG & $-40.93 \%$ \\
\hline$\square$ RYGB & $-56.17 \%$ \\
\hline$\square$ OAGB & $-62.89 \%$ \\
\hline SG VS. RYGB & $p<0.0001$ \\
\hline SG vS. OAGB & $p<0.0001$ \\
\hline RYGB VS. OAGB & $p=0.0489$ \\
\hline
\end{tabular}

Figure 3. HOMA-IR improvement 4 days after surgery (compared to OD)

Table IV. Change of HOMA-IR

\begin{tabular}{|c|c|c|c|c|c|c|}
\hline Checkpoint & Mean & SD & $\Delta$ (initial) & Value of $p$ & $\Delta$ (previous) & Value of $p$ \\
\hline \multicolumn{7}{|c|}{ SG $(n=24)$} \\
\hline $\mathrm{INI}$ & 4.60 & 1.53 & & & & \\
\hline OD & 3.83 & 1.36 & -0.77 & 0.0065 & -0.77 & 0.0065 \\
\hline $4 \mathrm{D}$ & 2.26 & 0.81 & -2.34 & $<0.0001$ & -1.57 & $<0.0001$ \\
\hline $1 \mathrm{M}$ & 2.04 & 0.80 & -2.56 & $<0.0001$ & -0.22 & 0.3591 \\
\hline $3 M$ & 1.87 & 0.61 & -2.73 & $<0.0001$ & -0.17 & 0.4221 \\
\hline $6 \mathrm{M}$ & 1.59 & 0.56 & -3.01 & $<0.0001$ & -0.28 & 0.1120 \\
\hline \multicolumn{7}{|c|}{ RYGB $(n=27)$} \\
\hline INI & 4.79 & 2.02 & & & & \\
\hline OD & 3.81 & 2.05 & -0.98 & 0.0827 & -0.98 & 0.0827 \\
\hline $4 \mathrm{D}$ & 1.67 & 0.61 & -3.12 & $<0.0001$ & -2.14 & $<0.0001$ \\
\hline $1 \mathrm{M}$ & 1.55 & 0.54 & -3.24 & $<0.0001$ & -0.12 & 0.4475 \\
\hline $3 M$ & 1.33 & 0.46 & -3.46 & $<0.0001$ & -0.22 & 0.1131 \\
\hline $6 \mathrm{M}$ & 1.21 & 0.44 & -3.58 & $<0.0001$ & -0.12 & 0.3318 \\
\hline \multicolumn{7}{|c|}{ OAGB $(n=30)$} \\
\hline INI & 4.93 & 1.65 & & & & \\
\hline OD & 3.88 & 1.51 & -1.05 & 0.0127 & -1.05 & 0.0127 \\
\hline $4 \mathrm{D}$ & 1.44 & 0.55 & -3.49 & $<0.0001$ & -2.44 & $<0.0001$ \\
\hline $1 M$ & 1.37 & 0.51 & -3.56 & $<0.0001$ & -0.07 & 0.6112 \\
\hline $3 M$ & 1.29 & 0.47 & -3.64 & $<0.0001$ & -0.07 & 0.5300 \\
\hline $6 M$ & 1.11 & 0.33 & -3.82 & $<0.0001$ & -0.19 & 0.0914 \\
\hline
\end{tabular}




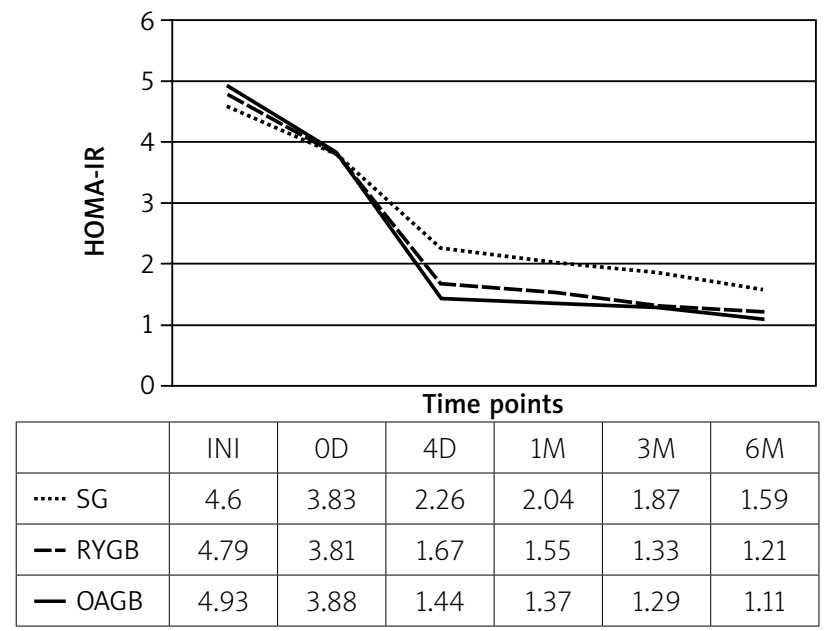

Figure 4. Evolution of HOMA-IR

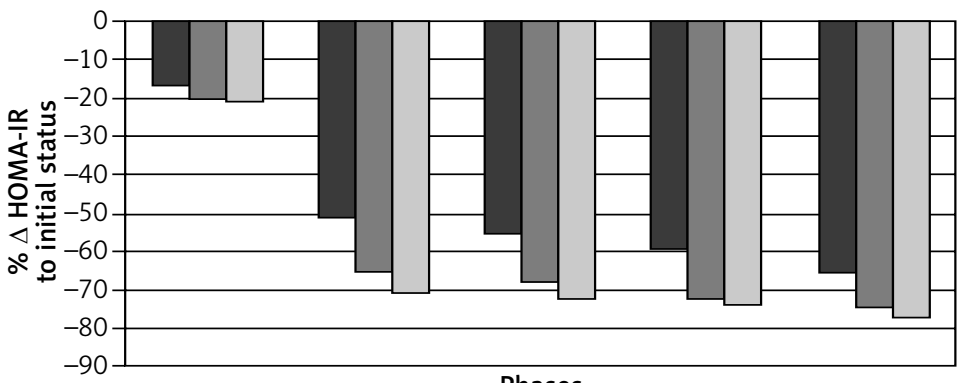

\begin{tabular}{|l|c|c|c|c|c|}
\hline & INI-OD & OD-4D & $4 D-1 M$ & $1 M-3 M$ & $3 M-6 M$ \\
\hline$\square$ SG & -16.73 & -50.87 & -55.65 & -59.35 & -65.43 \\
\hline$\square$ RYGB & -20.46 & -65.14 & -67.64 & -72.23 & -74.74 \\
\hline$\square$ OAGB & -21.3 & -70.79 & -72.21 & -73.83 & -77.48 \\
\hline SG vs. RYGB & $p=0.0661$ & $p<0.0001$ & $p=0.0012$ & $p=0.0130$ & $p=0.0171$ \\
\hline SG vs. OAGB & $p=0.0636$ & $p<0.0001$ & $p<0.0001$ & $p=0.0003$ & $p=0.0020$ \\
\hline RYGB vs. OAGB & $p=0.7146$ & $p=0.0817$ & $p=0.1936$ & $p=0.6892$ & $p=0.1464$ \\
\hline
\end{tabular}

Figure 5. HOMA-IR improvement compared to initial value

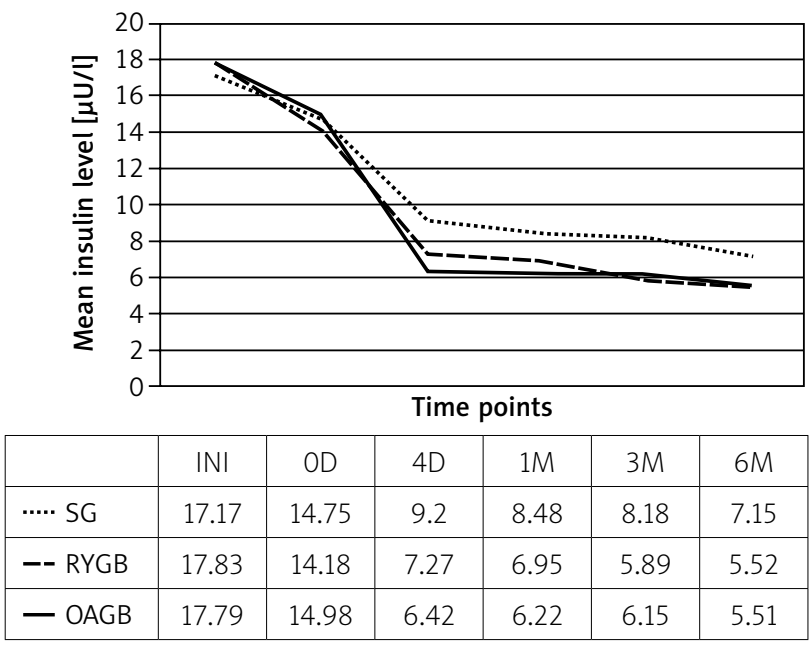

Figure 6. Evolution of insulin level 


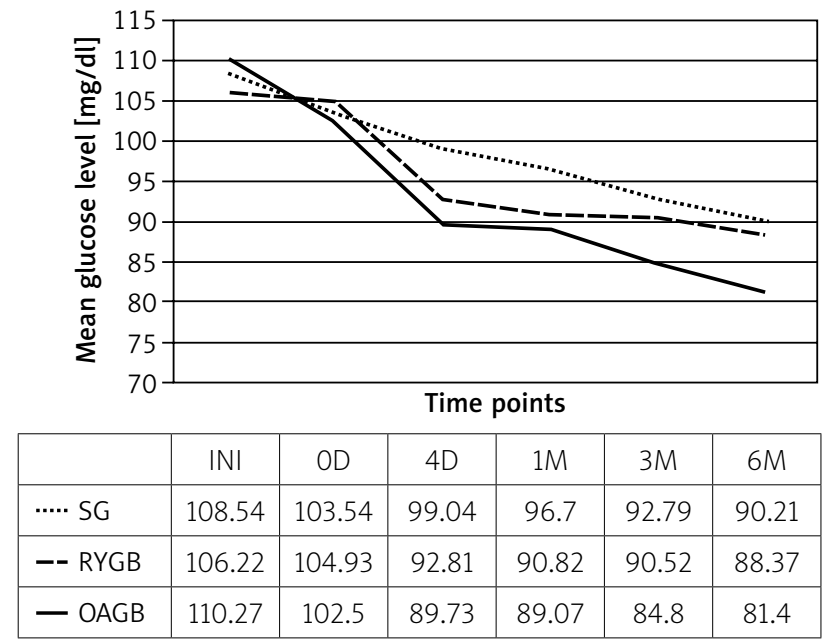

Figure 7. Evolution of glucose level

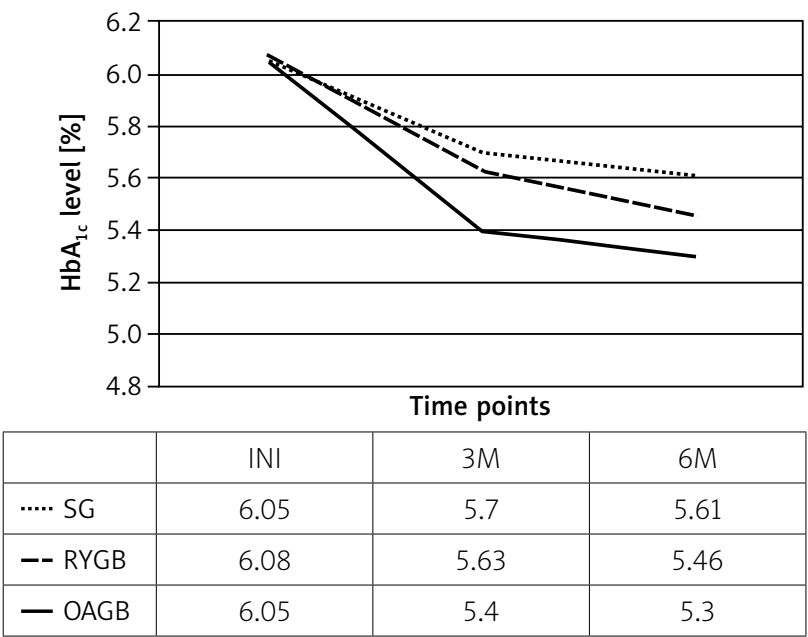

Figure 8. Evolution of $\mathrm{HbA}_{1 \mathrm{c}}$

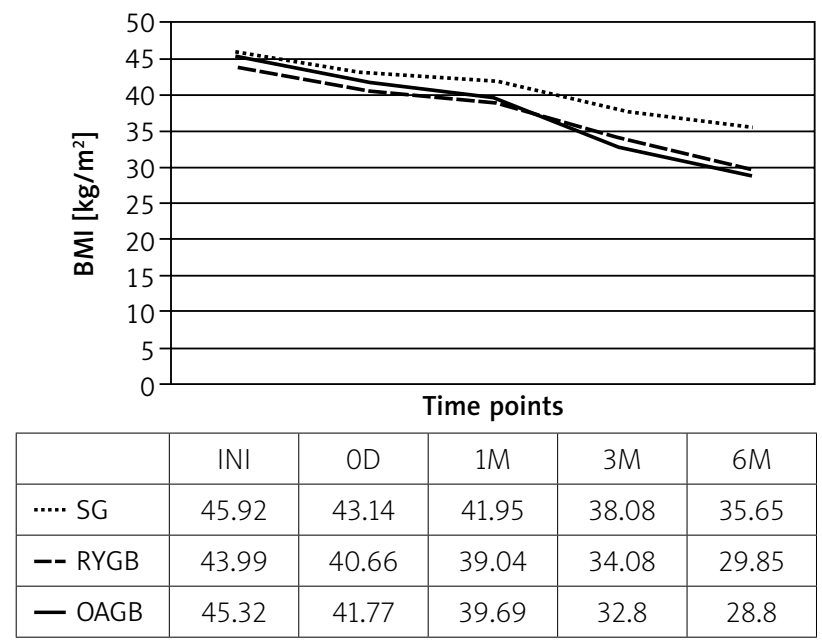

Figure 9. Evolution of BMI 
ration period but was not so strongly dependent on BMI decrease in the 1-6 months following surgery.

The early outcomes suggest that the mechanisms of IR control functioning in phase 2 (OD-4D) are the most crucial during the entire observation period. The results demonstrated that the procedures based on duodeno-intestinal exclusion involve a mechanism which more intensively influences IR improvement than only pure restriction does. Moreover, the length of the biliary limb and therefore the concentrated bile transit may play an important role in the glucose metabolism change. Detailed data are presented in Tables IV-VIII.

\section{Discussion}

Because the medical and demographic prognoses for the next 25 years present an alarming threat of a worldwide diabetes epidemic [45], the call for more intensive research to develop effective therapeutic models to prevent, treat, or at least slow down this detrimental trend should be propagated. Although bariatric surgery has recently been recognized as the most effective method of T2DM management, as supported by multiple scientific studies, many believe that understanding the mechanism of glucose metabolism based on the investigations of operated patients may lead to the invention of novel non-invasive therapies [46, 47].

Recently, despite the unclear mechanism of action, gastric bypass and biliopancreatic diversion/ duodenal switch have been used for T2DM treatment, as they are recognized as the most effective surgical procedures. It is commonly observed that the rapid postoperative improvement of glycemic

Table V. Change of mean plasma insulin level

\begin{tabular}{|c|c|c|c|c|c|c|}
\hline Checkpoint & Mean & SD & $\Delta$ (initial) & Value of $p$ & $\Delta$ (previous) & Value of $p$ \\
\hline \multicolumn{7}{|c|}{ SG $(n=24)$} \\
\hline $\mathrm{INI}$ & 17.17 & 4.31 & & & & \\
\hline OD & 14.75 & 4.12 & -2.42 & 0.0580 & -2.42 & 0.0580 \\
\hline $4 \mathrm{D}$ & 9.20 & 2.71 & -7.97 & $<0.0001$ & -5.55 & $<0.0001$ \\
\hline $1 \mathrm{M}$ & 8.48 & 2.64 & -8.70 & $<0.0001$ & -0.73 & 0.3664 \\
\hline $3 M$ & 8.18 & 2.50 & -8.99 & $<0.0001$ & -0.30 & 0.6942 \\
\hline $6 \mathrm{M}$ & 7.15 & 1.74 & -10.02 & $<0.0001$ & -1.03 & 0.1120 \\
\hline \multicolumn{7}{|c|}{ RYGB $(n=27)$} \\
\hline INI & 17.83 & 5.66 & & & & \\
\hline OD & 14.18 & 5.38 & -3.65 & 0.0186 & -3.65 & 0.0186 \\
\hline $4 \mathrm{D}$ & 7.27 & 2.54 & -10.57 & $<0.0001$ & -6.91 & $<0.0001$ \\
\hline $1 M$ & 6.95 & 2.44 & -10.88 & $<0.0001$ & -0.31 & 0.6181 \\
\hline $3 M$ & 5.89 & 1.60 & -11.94 & $<0.0001$ & -1.06 & 0.0647 \\
\hline $6 \mathrm{M}$ & 5.51 & 1.90 & -12.32 & $<0.0001$ & -0.37 & 0.4303 \\
\hline \multicolumn{7}{|c|}{ OAGB $(n=30)$} \\
\hline INI & 17.79 & 4.52 & & & & \\
\hline OD & 14.98 & 4.6 & -2.81 & 0.0203 & -2.81 & 0.0203 \\
\hline $4 \mathrm{D}$ & 6.42 & 1.97 & -11.37 & $<0.0001$ & -8.56 & $<0.0001$ \\
\hline $1 \mathrm{M}$ & 6.22 & 2.31 & -11.57 & $<0.0001$ & -0.2 & 0.7195 \\
\hline $3 M$ & 6.15 & 2.07 & -11.64 & $<0.0001$ & -0.07 & 0.9021 \\
\hline $6 \mathrm{M}$ & 5.51 & 1.6 & -12.28 & $<0.0001$ & -0.64 & 0.1855 \\
\hline
\end{tabular}


Table VI. Change of mean plasma glucose level

\begin{tabular}{|c|c|c|c|c|c|c|}
\hline Checkpoint & Mean & SD & $\Delta$ (initial) & Value of $p$ & $\Delta$ (previous) & Value of $p$ \\
\hline \multicolumn{7}{|c|}{ SG $(n=24)$} \\
\hline$|\mathrm{N}|$ & 108.54 & 14.60 & & & & \\
\hline OD & 103.54 & 14.57 & -5.00 & 0.2513 & -5.00 & 0.2513 \\
\hline $4 \mathrm{D}$ & 99.04 & 14.16 & -9.50 & 0.0302 & -4.50 & 0.2939 \\
\hline $1 \mathrm{M}$ & 96.71 & 12.20 & -11.83 & 0.0047 & -2.33 & 0.5530 \\
\hline $3 M$ & 92.79 & 11.22 & -15.75 & 0.0002 & -3.92 & 0.2628 \\
\hline $6 \mathrm{M}$ & 90.21 & 11.02 & -18.33 & $<0.0001$ & -2.58 & 0.4356 \\
\hline \multicolumn{7}{|c|}{ RYGB $(n=27)$} \\
\hline INI & 106.22 & 14.97 & & & & \\
\hline OD & 104.93 & 18.37 & -1.29 & 0.7784 & -1.29 & 0.7784 \\
\hline $4 \mathrm{D}$ & 92.81 & 11.33 & -13.41 & 0.0005 & -12.12 & 0.0052 \\
\hline $1 M$ & 90.82 & 8.98 & -15.4 & $<0.0001$ & -1.99 & 0.4777 \\
\hline $3 M$ & 90.52 & 10.74 & -15.7 & $<0.0001$ & -0.3 & 0.9118 \\
\hline $6 \mathrm{M}$ & 88.37 & 8.3 & -17.85 & $<0.0001$ & -2.15 & 0.4142 \\
\hline \multicolumn{7}{|c|}{ OAGB $(n=30)$} \\
\hline INI & 110.27 & 12.6 & & & & \\
\hline OD & 102.5 & 13.33 & -7.77 & 0.0239 & -7.77 & 0.0239 \\
\hline $4 \mathrm{D}$ & 89.73 & 10.5 & -20.54 & $<0.0001$ & -12.77 & 0.0001 \\
\hline $1 M$ & 89.07 & 8.16 & -21.2 & $<0.0001$ & -0.66 & 0.7867 \\
\hline $3 M$ & 84.8 & 6.47 & -25.47 & $<0.0001$ & -4.27 & 0.0285 \\
\hline $6 \mathrm{M}$ & 81.4 & 4.46 & -28.87 & $<0.0001$ & -3.4 & 0.0211 \\
\hline
\end{tabular}

Table VII. Change of mean $\mathrm{HbA}_{1 \mathrm{c}}$

\begin{tabular}{|c|c|c|c|c|c|c|}
\hline Checkpoint & Mean & SD & $\Delta$ (initial) & Value of $p$ & $\Delta$ (previous) & Value of $p$ \\
\hline \multicolumn{7}{|c|}{ SG $(n=24)$} \\
\hline INI & 6.06 & 0.34 & & & & \\
\hline $3 M$ & 5.72 & 0.39 & -0.34 & 0.0029 & -0.35 & 0.0029 \\
\hline $6 \mathrm{M}$ & 5.61 & 0.34 & -0.45 & $<0.0001$ & -0.11 & 0.3135 \\
\hline \multicolumn{7}{|c|}{ RYGB $(n=27)$} \\
\hline INI & 6.08 & 0.59 & & & & \\
\hline $3 M$ & 5.63 & 0.31 & -0.45 & 0.0009 & -0.45 & 0.0009 \\
\hline $6 \mathrm{M}$ & 5.4 & 0.29 & -0.68 & $<0.0001$ & -0.23 & 0.0069 \\
\hline \multicolumn{7}{|c|}{ OAGB $(n=30)$} \\
\hline INI & 6.06 & 0.27 & & & & \\
\hline $3 M$ & 5.47 & 0.32 & -0.59 & $<0.0001$ & -0.59 & $<0.0001$ \\
\hline $6 \mathrm{M}$ & 5.3 & 0.33 & -0.76 & $<0.0001$ & -0.17 & 0.0474 \\
\hline
\end{tabular}


Table VIII. Change of BMI

\begin{tabular}{|c|c|c|c|c|c|c|}
\hline Checkpoint & Mean & SD & $\Delta$ (initial) & Value of $p$ & $\Delta$ (previous) & Value of $p$ \\
\hline \multicolumn{7}{|c|}{ SG $(n=24)$} \\
\hline INI & 45.90 & 6.52 & & & & \\
\hline OD & 42.13 & 6.27 & -3.77 & 0.0518 & -3.77 & 0.0518 \\
\hline $1 \mathrm{M}$ & 41.90 & 6.00 & -4.00 & 0.0359 & -0.23 & 0.8994 \\
\hline $3 M$ & 38.00 & 6.54 & -7.90 & 0.0002 & -3.90 & 0.0408 \\
\hline $6 \mathrm{M}$ & 35.70 & 6.55 & -10.20 & $<0.0001$ & -2.30 & 0.2398 \\
\hline \multicolumn{7}{|c|}{ RYGB $(n=27)$} \\
\hline INI & 43.99 & 5.89 & & & & \\
\hline OD & 40.66 & 6 & -3.33 & 0.0446 & -3.33 & 0.0446 \\
\hline $1 M$ & 39.04 & 5.12 & -4.95 & 0.0018 & -1.62 & 0.2908 \\
\hline $3 M$ & 34.08 & 5.83 & -9.91 & $<0.0001$ & -4.96 & 0.0016 \\
\hline $6 \mathrm{M}$ & 29.85 & 5.14 & -14.14 & $<0.0001$ & -4.23 & 0.0066 \\
\hline \multicolumn{7}{|c|}{ OAGB $(n=30)$} \\
\hline INI & 45.32 & 4.82 & & & & \\
\hline OD & 40.77 & 4.18 & -4.55 & 0.0002 & -4.55 & 0.0002 \\
\hline $1 M$ & 39.69 & 4.32 & -5.63 & $<0.0001$ & -1.08 & 0.3292 \\
\hline $3 M$ & 32.8 & 3.94 & -12.52 & $<0.0001$ & -6.89 & $<0.0001$ \\
\hline $6 \mathrm{M}$ & 28.8 & 3.26 & -16.52 & $<0.0001$ & -4.00 & $<0.0001$ \\
\hline
\end{tabular}

control is weight loss independent. The remission or partial remission of T2DM is experienced within the first postoperative month when the weight reduction is not significant $[24,25,48]$. It has been well documented that enhanced insulin secretion and decreased insulin resistance are associated with higher activity of the well-known human incretin, glucagon-like peptide-1 (GLP-1), in the early response after bypass procedures [24, 25].

A positive byproduct of the studies involving RYGB and BPD-DS patients was the discovery and production of medications that enhance incretin activity [49].

Though the effectiveness of incretin analogues in T2DM therapy has already been proven, the alteration of glucose metabolism via an enhanced incretin effect appears to be only a supporting and not primary mechanism in diabetics who experienced immediate or early remission after gastric bypass surgery. It has been reported that blocking this mechanism using different anti-incretin agents in patients after RYGB is less influential than previ- ously believed and cannot definitely hamper IR improvement [50].

Furthermore, over $50 \%$ of diabetic patients experience an immediate improvement of glucose balance without anti-diabetic medications within just a few postoperative days when they are discharged home before initiating per os feeding (only clear fluids), which is the condition generally considered to be indispensable to provoke the incretin reactions $[27,51,52]$. Such impressive clinical observations were noted to occur more often after BP operations as opposed to solely restrictive procedures [53].

Some authors question such a rapid response following gastric bypass or claim that prolonged calorie restriction is the source of the quick improvement in IR, a status which accompanies all extensive Gl surgery [54].

Additionally, studies based on hyperinsulinemic euglycemic clamp have confirmed the fast IR improvement, but still the interval from the surgery to assessment was not shorter than a few weeks, 
which does not definitively correlate with the clinical observations $[55,56]$.

In order to support some extra metabolic value of $\mathrm{GB}$ procedures compared to the pure restrictive operations, the authors of this study prospectively assessed the main laboratory parameters of glucose metabolism in obese individuals with IR in different stages of the bariatric management, comparing patients who underwent sleeve gastrectomy and two types of gastric bypass.

To ensure a similar restrictive component, the gastric reservoirs in both SG and GB were constructed in the same manner.

Like other researchers [27], we chose a very simple parameter, HOMA-IR, to measure insulin sensitivity, deciding against a more precise one dedicated for IR assessment tests such as clamp. This solution, convenient for the investigated subjects because of its non-invasiveness, was well tolerated and enabled us to recruit a representative number of patients to each group $(3 \times 30)$ in quite a short time.

As expected, IR improvement was observed (ca $20 \%$ ) in the preoperative 3-month preparation period when patients in all groups reduced their daily energy intake to ca 1000-1200 kcal. It was not so spectacular compared to what was observed in the first 4 days postoperatively, when HOMA-IR decreased $41-63 \%$ from the value obtained on the day of admission for surgery. The significant difference of $\triangle \mathrm{HOMA}-\mathrm{IR}$ between the pure restrictive procedure (SG) and RYGB or OAGB exposed, apart from the result of extreme caloric restriction, the additional important role of the excluded part of the digestive tract in alteration of glucose homeostasis.

We observed the same trend during the follow-up visits (1-6 months), as previously reported by Faria et al. [27], that the HOMA-IR evolved smoothly down in consecutive periods postoperatively, but the change was never so remarkable as directly after the surgery, even in the stages when incretin mechanisms could be strongly initiated or weight/fat reduction could influence the IR improvement.

The ultra-fast response after $\mathrm{GB}$ procedures may support Rubino's "foregut theory" [57] propagating the key role of glucose metabolism improvement resulting from the exclusion of the duodenum and part of the jejunum more than the theory of the anti-diabetic effect of accelerated drive of active undigested food to distally located incretin-triggering receptors $\alpha$ and $\mathrm{K}[58,59]$.
This immediate IR improvement seems not to be related to the increased insulin production, which is expected to be the effect of the postprandial incretin reaction, but is associated rather with the correction of fasting hyperinsulinemia $[55,56,60]$. The increased sensitivity to insulin is considered therefore as an important component of HOMA-IR which is improved rapidly after the operation in the period when patients do not start eating [27, 32].

The influence of the length of the excluded part of the digestive tract on the dynamics of glucose metabolism improvement may also be an intriguing issue for reflection.

Some studies [61, 62] have demonstrated better T2DM resolution after RYGB where the bilio-pancreatic limb was constructed longer than the traditional 50-100 cm, maintaining the same alimentary limb. Complete diabetes remission without anti-diabetic medications was observed more frequently after RYGB with extended BL postoperatively from 1 to 24 months also in our material [63]. Though the shortened (by elongating the $\mathrm{BL}$ ) common channel might have a beneficial influence on glycemia control by reducing the food content absorption area in long-term observation, shortly after RYGB when the nourishment volume is extremely restricted anyway, that part of the intestine with extended undiluted bile passage may instead play a role in immediate glucose metabolism improvement [63].

Moreover, the basic aim of BPD/DS was not only to maintain a limited distance for the common bile and food flow but in contrast to long limb Roux en $\mathrm{Y}$ gastric bypass to exclude a longer BL than AL [64]. It has been shown that this combination of GI tract modification provides more complete and long-term T2DM remission, with a comparable risk of nutritional deficiency [34].

Finally, the link between the extended space for the separated bile passage and the progressive glycemic control has been exposed also after the recently widely promoted variety of $\mathrm{GB}$ - one-anastomosis gastric bypass. This evolved from the mini gastric bypass, originally described by Rutledge [38], a bariatric operation which although anatomically considered to be only a modification of GB, metabolically imitates a more aggressive form of bariatric surgery - BPD/DS [39].

The resemblance to RYGB is derived from the scale of the restriction and from the proportionally longer common limb, which result in a lower risk of 
malnutrition than after BPD/DS. The 2-3 times longer $\mathrm{BL}$ created in OAGB is believed to alter more intensively the postoperative metabolic response than after Roux-en-Y type [39].

The propagators of OAGB such as Lee or GarciaCaballero favor its better anti-diabetic competence over RYGB in mid- and long-term observation [37, 38].

Weiner et al. appreciated its effectiveness and recommended it beside BPD/DS as the procedure of choice to complete the bariatric management after failed sleeve gastrectomy [65].

The present authors, encouraged by the midand long-term benefits of OAGB, included a group of patients operated on by this method in the present study, intending to assess the influence of extended transit of concentrated bile on IR improvement in the ultra-short, short and early postoperative period.

The HOMA-IR change in the period between the day of admission and the 4th day was the most remarkable after OAGB $(-\Delta 63 \%$ vs. $-\Delta 56 \%$ after RYGB and $-\Delta 41 \%$ after $\mathrm{SG})$. Correlating these findings with the long-term results demonstrating the improvement of glucose metabolism may lead to the conclusion that the processes occurring in the excluded duodenum and part of the jejunum may play the crucial role in glucose homeostasis after GB procedures [66].

The mechanism of rapid IR improvement after GB consistent with the "foregut theory" still requires explanation.

Since Troy et al. proposed in an animal model [67] the reliable hypothesis of a key role of fasting intestinal gluconeogenesis in an incretin-independent mechanism of increasing the sensitivity to insulin after GB, it has not been supported univocally in human studies [68].

The beneficial metabolic effect after duodeno-jejunal exclusion on glycemic control may be attributed to the substantially high undiluted bile concentration in the intestinal section proximally to the anastomosis where the bile is mixed together with food [66]. The bile ingredients therefore, reabsorbed and transferred via the portal vein system, may carry the intensified signal to change the insulin resistance in the liver and other metabolically active organs or tissues [69]. It has been reported by Le Roux's group [32] that reabsorbed primarily bile acids can function as hormones through the farnesoid $X$ receptor or $G$ protein-coupled bile acid receptor 1 and affect the glucose and lipid transformations. Bearing in mind the fact that ca $400-800 \mathrm{ml}$ of bile can be produced and delivered to the alimentary tract daily, contained undiluted in the proximal intestine it may constitute a powerful hormonally active system determining glucose homeostasis $[66,69]$.

Although many surgeons intuitionally tend to prolong the $B L$ in different operative solutions in T2DM patients, the assessment of the correlation between the length of the excluded $B L$ and the strength of the signaling coming from the reabsorbed bile components leading to the IR improvement would facilitate our understanding of the potential role of bile in metabolic regulation.

\section{Conclusions}

Among all the factors generated by the bariatric management of obese individuals with glucose intolerance, the type of operation is recognized as the most important in insulin resistance improvement based on HOMA-IR assessment. The most significant change is observed on the $4^{\text {th }}$ day after the surgery and therefore is not dependent on the weight/ fat reduction, and the role of the incretin mechanism is questionable because of fasting from caloric food intake. The significant difference in the ultra-fast and early response after restrictive sleeve gastrectomy vs both types of gastric bypass supports the conception of metabolic competence of duodeno-jejunal exclusion.

Altered bile flow after duodeno-jejunal exclusion may be responsible for the enhanced glucose metabolism improvement in postoperatively fasting patients. The reabsorption of the bile ingredients facilitating the rapid metabolic response may be more intensive in a longer biliary limb. Further investigation of the influence of bile activity in the bypassed jejunum on glucose homeostasis is necessary to thoroughly analyze the gastro-intestinal anti-diabetic mechanisms.

\section{Conflict of interest}

The authors declare no conflict of interest.

\section{References}

1. Zimmet P. The burden of type 2 diabetes: are we doing enough? Diabetes Metab 2003; 29: 6S9-18.

2. Stratton IM. Association of glycemia with micro and macrovascular complications of type 2 diabetes prospective observational study. BMJ 2000; 321: 405-12. 
3. Defronzo RA. Pathogenesis of type 2 diabetes mellitus. Med Clin North Am 2004; 88: 787-835.

4. Gastaldelli A, Ferrannini E, Miyazaki Y, et al. Beta-cell dysfunction and glucose intolerance: results from San Antonio metabolizm study. Diabetologia 2004; 47: 31-9.

5. Wing RR, Blair EH, Bononi P, et al. Caloric restriction per se is a significant factor in improvements in glycemic control and insulin sensitivity during weight loss in obese NIDDM patients. Diabetes Care 1994; 17: 130-6.

6. Weiss EP, Racette SB, Villareal DT, et al. Improvements in glu cose tolerance and insulin action induced by increasing energy expenditure or decreasing energy intake: a randomized controlled trial. Am J Clin Nutr 2006; 84: 1033-42.

7. Kelley DE, Wing R, Buonocore C, et al. Relative effects of calorie restriction and weight loss in noninsulin-dependent diabetes mellitus. J Clin Endocrinol Metab 1993; 77: 1287-93.

8. Larson-Meyer DE, Heilbronn LK, Redman LM, et al. Effect of calorie restriction with or without exercise on insulin sensitivity, beta-cell function, fat cell size, and ectopic lipid in overweight subjects. Diabetes Care 2006; 29: 1337-44.

9. Unger RH. Minireview: weapons of lean body mass destruction: the role of ectopic lipids in the metabolic syndrome. Endocrinology 2003; 144: 5159-65.

10. Halperin F, Ding SA, Simonson DC, et al. Roux-en-Y gastric bypass surgery or lifestyle with intensive medical management in patients with type 2 diabetes: feasibility and 1-year results of a randomized clinical trial. JAMA Surg 2014; 149: 716-26.

11. Sjostrom L, Lindross AK, Peltonen M, et al.; Swedish Obese Subject Study Scientific Group. Lifestyle, diabetes and cardiovascular risk factors 10 years after bariatric surgery. N Engl J Med 2004; 351: 2683-93.

12. Lehmann A, Bobowicz M, Lech P, et al. Comparison of percentage excess weight loss after laparoscopic sleeve gastrectomy and laparoscopic adjustable gastric banding. Videosurgery Miniinv 2014; 9: 351-6.

13. Schauer PR, Kashyap SR, Wolski K, et al. Bariatric surgery versus intensive medical therapy in obese patients with diabetes. NEJM 2012; 366: 1567-76.

14. Meneghini LF. Impact of bariatric surgery on type 2 diabetes. Cell Biochem Biophys 2007; 48: 97-102.

15. Adams TD, Gress RE, Smith SC, et al. Long term mortality after gastric by-pass surgery. N Engl J Med 2007; 357: 753-61.

16. Scopinaro N, Marinari GM, Camerini GB, et al. Specific effects of BPD on the major components of metabolic syndrom: a long term follow-up study. Diabetes Care 2005; 28: 2406-11.

17. Paluszkiewicz R, Kalinowski P, Wróblewski T, et al. Prospective randomized clinical trial of laparoscopic sleeve gastrectomy versus open Roux-en-Y gastrin bypass for the management of patients with morbid obesity. Videosurgery Miniinv 2012; 7: 225-32.

18. Karcz WK, Kuesters S, Marjanovic G, et al. Duodeno-enteral omega switches - more physiological techniques in metabolic surgery. Videosurgery Miniinv 2013; 8: 273-9.

19. Thaler JP, Cummings DE. Minireview: hormonal and metabolic mechanisms of diabetes remission after gastrointestinal surgery. Endocrinology 2009; 150: 2518-25.

20. Nannipieri $M$, Baldi S, Mari A, et al. Roux-en-Y gastric bypass and sleeve gastrectomy: mechanisms of diabetes remission and role of gut hormones. J Clin Endocrinol Metab 2013; 98 : 4391-9.

21. Kotronen A, Juurinen I, Tikkainen $M$, et al. Increased liver fat, impaired insulin clearance, hepatic and adipose tissue insulin resistance in T2DM. Gastroenterology 2008; 135: 122-30.

22. Kaska L, Mika A, Stepnowski P, et al. The relationship between specific fatty acids of serum lipids and serum high sensitivity C-reactive protein level in morbidly obese women. Cell Physiol Biochem 2014; 34: 1101-8.

23. Salinari S, Bertuzzi A, Asnaghi S, et al. First-phase insulin secretion restoration and differentia response to glucose load depending on the route of the administration in T2DM subjects after bariatric burgery. Diabetes Care 2009; 32: 375-80.

24. Bikman BT, Zheng D, Pories WJ, et al. Mechanism for improved insulin sensivity after gastric bypass surgery. J Clin Endocrinol Metab 2008; 93: 4656-63.

25. Laferrere B, Heshka S, Wang K, et al. Incretin levels and effect are markedly enhanced 1 month after RYGB surgery in obese patients with T2DM. Diabetes Care 2007; 30: 1709-16.

26. Cho YM. A gut feeling to cure diabetes: potential mechanisms of diabetes remission after bariatric surgery. Diabetes Metab J 2014; 38: 406-15.

27. Faria G, Preto J, Lima da Costa E, et al. Acute improvement in insulin resistance after laparoscopic Roux-en-Y gastric bypass: is 3 days enough to correct insulin metabolism? Obesity Surg 2013; 23: 103-10.

28. Laferrère $B$. Diabetes remission after bariatric surgery: is it just the incretins? Int J Obes (Lond) 2011; 35 Suppl 3: S22-5.

29. Cohen RV, Pinheiro JC, Schiavo CA, et al. Effects of gastric bypass surgery in patients with type 2 diabetes and only mild obesity. Diabetes Care 2012; 35: 1420-8.

30. Laferrere B. Do we really know why diabetes remits after gastric bypass surgery? Endocrine 2011; 40: 162-7.

31. Camastra S, Gastaldelli A, Mari A. Early and longer term effects of gastric bypass surgery on tissue-specific insulin sensitivity and beta-cell function in morbidly obese patients with and without T2DM. Diabetologia 2011; 54: 2093-102.

32. Pournaras DJ, Glicksman C, Vincent RP. The role of bile after Roux-en-Y gastric bypass in promoting weight loss and improving glycaemic control. Endocrinology 2012; 153: 3613-9.

33. Mingrone G, Castagneto-Gissey L. Mechanisms of early improvement/resolution of type 2 diabetes after bariatric surgery. Diabetes Metab 2009; 35: 518-23.

34. Mingrone G, Panunzi S, De Gaetano A, et al. Bariatric surgery versus conventional medical therapy for type 2 diabetes. N Engl J Med 2012; 366: 1577-85.

35. Scopinaro N, Adami GF, Papadia FS, et al. Effects of biliopanceratic diversion on type 2 diabetes in patients with BMI 25 to 35. Ann Surg 2011; 253: 699-703.

36. Victorzon M. Single-anastomosis gastric bypass: better, faster, and safer? Scand I Surg 2015; 104: 48-53.

37. García-Caballero M, Valle M, Martínez-Moreno JM. Resolution of diabetes mellitus and metabolic syndrome in normal weight 24-29 BMI patients with one anastomosis gastric bypass. Nutr Hosp 2012; 27: 623-31.

38. Rutledge R. The mini-gastric bypass: experience with the first 1,274 cases obesity. Surgery 2001; 11: 276-80. 
39. Lee WJ, Ser KH, Lee YC, et al. Laparoscopic Roux-en-Y vs. mini-gastric bypass for the treatment of morbid obesity: a 10year experience. Obes Surg 2012; 22: 1827-34.

40. Wallace TM, Levy JC, Matthews DR. Use and abuse of HOMA modeling. Diabetes Care 2004; 27: 1487-95.

41. Fried M, Yumuk V, Oppert JM, et al. Interdisciplinary European guidelines on metabolic and bariatric surgery. Obes Facts 2013; 6: 449-68.

42. Kaska L, Proczko M, Stefaniak TJ, et al. Redesigning the process of laparoscopic sleeve gastrectomy based on risk analysis resulted in 100 consecutive procedures without complications. Videosurgery Miniinv 2013; 8: 289-300.

43. Olbers T, Olsén MF, Maleckas A, Lönroth H. Randomized clinical trial of laparoscopic Roux-en-Y gastric bypass versus laparoscopic vertical banded gastroplasty for obesity. Br J Surg 2005 92: $557-62$

44. www.thebloodcode.com/homa-ir-calculator

45. Lebovitz $H$. Type 2 diabetes mellitus - current therapies and the emergence of surgical options. Nature Rev Endocrinol 2011; 7: 408-19.

46. Gil H, Dolores M, Alarcón P, et al. Surgical treatment of type 2 diabetes. Pharmacol Pharmacy 2014; 5; 24.

47. Cummings DE. Endocrine mechanisms mediating remission of diabetes after gastric bypass surgery. Int J Obes 2009; 33: S33-40.

48. Rubino F, Forgione A, Cummings DE, et al. The mechanism of diabetes control after gastrointestinal bypass reveals a role of proximal small intestine in the pathophysiology of T2DM. Ann Surg 2006; 244: 741-9.

49. Gale EAM. GLP-1-based therapies and the exocrine pancreas: more light, or just more heat? Diabetes 2012 61; 986-8.

50. Vetter ML, Wadden TA, Teff KL, et al. GLP-1 plays a limited role in improved glycemia shortly after Roux-en-Y gastric bypass: a comparison with intensive lifestyle modification. Diabetes 2015; 64: 434-46.

51. Roslin MS, Dudiy Y, Brownlee A, et al. Response to glucose tolerance testing and solid high carbohydrate challenge: comparison between Roux-en-Y gastric bypass, vertical sleeve gastrectomy, and duodenal switch. Surg Endosc 2014; 28: 91-9.

52. Paranjape SA, Chan O, Zhu W, et al. Improvement in hepatic insulin sensitivity after Roux-en-Y gastric bypass in a rat mode of obesity is partially mediated via hypothalamic insulin action. Diabetologia 2013; 56: 2055-8.

53. Kashyap SR, Daud S, Kelly KR, et al. Acute effects of gastric bypass vs gastric restrictive surgery on beta-cell function and insulinotropic hormones in severely obese patients with T2DM. Inter J Obes 2010; 34: 462-71.

54. Lingvay I, Guth E, Islam A, Livingston E. Rapid improvement in diabetes after gastric bypass surgery: is it the diet or surgery? Diabetes Care 2013; 36: 2741-7.

55. Chambers AP, Jessen L, Ryan KK, et al. Weight-independent changes in blood glucose homeostasis after gastric bypass or vertical sleeve gastrectomy in rats. Gastroenterology 2011; 141: 950-8.

56. Bradley D, Magkos F, Eagon JC, et al. Matched weight loss induced by sleeve gastrectomy or gastric bypass similarly im- proves metabolic function in obese subjects. Obesity (Silver Spring) 2014; 22: 2026-31.

57. Rubino F, Marescaux J. Effect of duodenal-jejunal exclusion in a non-obese animal model of type 2 diabetes: a new perspective for an old disease. Ann Surg 2004; 239: 1-11.

58. Kamvissi V, Salerno A, Bornstein SR, et al. Incretins or anti-incretins? A new model for the "entero-pancreatic axis". Horm Metab Res 2015; 47: 84-7.

59. Patriti A, Facchiano E, Sanna A, et al. The enteroinsular axis and the recovery from type 2 diabetes after bariatric surgery. Obes Surg 2004; 14: 840-8.

60. Bojsen-Møller KN, Dirksen C, Jørgensen NB, et al. Early enhancements of hepatic and later of peripheral insulin sensitivity combined with increased postprandial insulin secretion contribute to improved glycemic control after RouX-en-Y gastric bypass. Diabetes 2014; 63: 1725-37.

61. Pinheiro JS, Schiavon CA, Pereira PB, et al. Long-long limb Rouxen-Y gastric bypass is more efficacious in treatment of type 2 diabetes and lipid disorders in super-obese patients. Surg Obes Relat Dis 2008; 4: 521-7.

62. Nergaard BJ, Leifsson BG, Hedenbro J, Gislason H. Gastric bypass with long alimentary limb or long pancreato-biliary limb - long-term results on weight loss, resolution of co-morbidities and metabolic parameters. Obes Surg 2014; 24: 1595-602.

63. Kaska L, Kobiela J, Proczko M, et al. Does the length of the biliary limb influence medium-term laboratory remission of type 2 diabetes mellitus after RouX-en-Y gastric bypass in morbidly obese patients? Videosurgery Miniinv 2014; 9: 31-9.

64. Scopinaro N. Thirty-five years of biliopancreatic diversion: notes on gastrointestinal physiology to complete the published information useful for a better understanding and clinical use of the operation. Obes Surg 2012; 22: 427-32.

65. Weiner RA, Theodoridou S, Weiner S. Failure of laparoscopic sleeve gastrectomy: further procedure? Obes Facts 2011; 4 Suppl 1: 42-6.

66. Taylor DR, Alaghband-Zadeh J, Cross GF, et al. Urine bile acids relate to glucose control in patients with type 2 diabetes mellitus and a body mass index below $30 \mathrm{~kg} / \mathrm{m}^{2}$. PLoS One 2014; 9: e93540.

67. Troy S, Soty M, Ribeiro L, et al. Intestinal gluconeogenesis is a key factor for early metabolic changes after RYGB but not after AGB in mice. Cell Metabol 2008; 8: 201-11.

68. Hayes MT, Foo J, Besic V, et al. Is intestinal gluconeogenesis a key factor in the early changes in glucose homeostasis following gastric bypass? Obes Surg 2011; 21: 759-62.

69. Sweeney TE, Morton JM. Metabolic surgery: action via hormonal milieu changes, changes in bile acids or gut microbiota? A summary of the literature. Best Pract Res Clin Gastroenterol 2014; 28: 727-40.

Received: 25.01.2015, accepted: 16.03.2015. 